\title{
National Institute for Occupational Safety and Health Promoting productive workplaces through safety and health research
}

NIOSH at a Glance

NIOSH's mission is to generate new knowledge in occupational safety and health and to transfer that knowledge to employers and workers. We are solutions people. By working collaboratively with public and private sector partners, NIOSH transfers its research findings into cost-effective solutions to make work safer, healthier and more productive for workers, employers, and the Nation. NIOSH is part of the Centers for Disease Control and Prevention in the Department of Health and Human Services.

\section{The Way We Work}

Relevance - Employer and worker needs for solutions drive research programs at NIOSH. We focus our efforts on ten industry sectors to address the specific problems for which research solutions are needed.

Quality - Sound science, the highest level of data quality, and independent peer review are hallmarks of $\mathrm{NIOSH}$ science.

Collaboration - Different than the regulatory approach to safety and health, NIOSH works cooperatively with employers and workers to adapt research findings into workable solutions.

Accountability - NIOSH aims to use its funding to maximize the taxpayer investment in research.

\section{Partnerships Lead to Safer and More Productive Workplaces}

Construction: Highway construction workers are at the frontline of building and repairing the nation's roads, but may face exposure to dust that can cause lung cancer. Working with the asphalt industry and labor partners, NIOSH designed, tested, and implemented simple retrofits for existing asphalt milling machines to reduce worker exposure. Industry partners voluntarily installed NIOSH recommended dust controls to new half-lane and larger cold-milling machines. Manufacturers with $80 \%$ market share began putting the controls on new machines nearly three years ahead of schedule.

Oil and Gas Extraction: The hydraulic fracturing industry employs hundreds of thousands of workers in both rural and metropolitan areas. NIOSH field research found high crystalline silica exposures among workers in hydraulic fracturing operations, placing them at risk of irreversible lung disease. In response, NIOSH worked with partners to develop the NIOSH mini-baghouse retrofit assembly, an effective and inexpensive engineering solution that can reduce silica emissions on sand moving equipment by $99 \%$. Major companies responded positively and quickly to the $\mathrm{NIOSH}$ work, voluntarily redesigning their equipment to protect workers from silica dust.

Mining: Providing adequate lighting for miners to work safely is a challenge in underground mines. Inadequate light contributes to miner slips, trips, falls and machine related injuries. NIOSH researchers partnered with two underground coal mines
We use a Burden, Need, and Impact method to ensure accountability for our appropriated dollars.

Partnership - For over 20 years, the National Occupational Research Agenda (NORA) has been the way NIOSH connects to the Nation's industry sectors. NORA is a public-private partnership to identify critical needs and to optimize the transfer of science findings where they can do the most good.

Impact - NIOSH is results driven. We are committed to evaluating our performance and measuring the impact of our research solutions in the real world.

and a technology company to develop a new LED cap lamp for miners. The new cap lamp cut glare in half and provided better peripheral motion vision. Miners can also adjust the distribution and intensity of the light to suit their work tasks. This innovation contributed to changes in five industry voluntary consensus standards for cap lamps used in mines, leading to voluntary changes in the manufacturing of all cap lamps for use in underground mines and improved safety for miners.

Firefighting: $\mathrm{NIOSH}$ works with both structural and wildland firefighters to understand and prevent a range of health issues, from cancer to smoke inhalation to injuries. NIOSH collaborated with the firefighter community, firefighter equipment manufacturers, and the National Fire Protection Agency (NFPA) to collect and analyze data on firefighter body size and shape that aids in the design of better fitting firefighter personal protective equipment.

Maritime: In commercial fishing, $86 \%$ of fatalities are caused by drowning. Wearing a personal flotation device (PFD) is a simple way for workers to protect themselves, but many work without one. NIOSH collaborated with fishing workers to understand their concerns about wearing PFDs and what would make them more willing to wear this critical piece of safety equipment. The results of this work were used by a PFD manufacturer to make an innovative 'tactical deck vest' that can be worn comfortably and continuously, keeping workers afloat if they should go overboard.

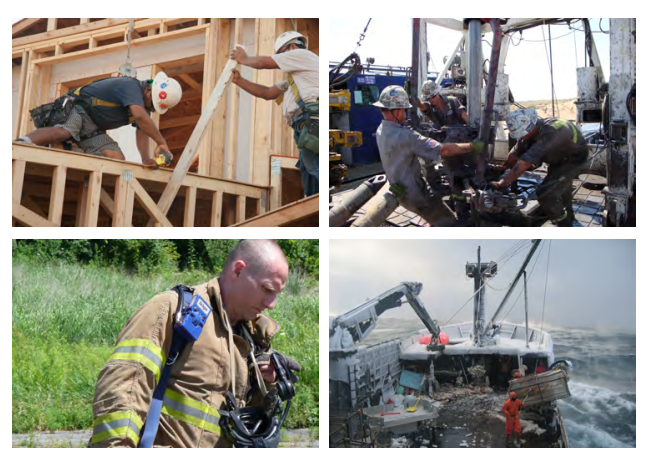

\section{Creative Tools with Small Businesses in Mind}

The Ladder Safety App, NIOSH's award winning first mobile application, has over 112,000 downloads. Falls from ladders are common in the construction industry but preventable. The free NIOSH Ladder Safety app provides visual and audio signals to help users set the proper angle. It can be readily accessed at the worksite, making it especially helpful for small construction businesses. State officials, industry leaders, and safety professionals have promoted the app, and many companies have incorporated the use of the app as part of their safety practices.

\section{Frontline Service}

$\mathrm{NIOSH}$ field scientists provide individualized assessments of potential workplace hazards through Health Hazard Evaluations. They are available by request from employers, workers and worker representatives.

\section{Preparing Tomorrow's Workforce for Safe and Healthy Work}

The Safe•Skilled•Ready Workforce program aims to equip young people and new hires with eight, transferable, work-readiness competencies to help protect them on the job now and throughout their lives. NIOSH worked with educators and job training experts to createYouth@Work: Talking Safety, a free, foundation curriculum in occupational safety and health. It

is customized for each of the 50 states.

\section{YOUTH@WORK}

$$
\text { Talking Safety }
$$

Visit https://www.cdc.gov/niosh to learn more 